\title{
The Rise of Environmentalism, Pollution Taxes and Intra-industry Trade
}

\author{
Toke Skovsgaard Aidt* \\ University of Cambridge and Jesus College
}

\begin{abstract}
Many industrialized countries have experienced an increase in environmental awareness and support to green lobby groups in past decades. This paper develops a political-economy model to investigate to what extent a rise of environmentalism, via the induced change in political power structures, can successfully encourage higher pollution taxes and reduce pollution. The model focuses on special-interest group politics, intra-industry trade and a transnational environmental externality. The main finding is that a rise of environmentalism is not sufficient to protect the environment when pollution is relatively immobile and environmentalists are concerned with environmental damage in other countries than their own.

Keywords: Transnational externalities, pollution taxes, lobby groups and trade.

JEL Classification: D72, Q28, F12.
\end{abstract}

*University of Cambridge, Faculty of Economics and Politics, Austin Robinson Building, Sidgwick Avenue, Cambridge CB3 9DD, UK. Phone: +44 122333 5231, Fax: +44 122333 5375, E-mail: toke.aidt@econ.cam.ac.uk. 


\section{The Rise of Environmentalism, Pollution Taxes and Intra-industry Trade}

\section{Introduction}

During the past three decades, public awareness about environmental problems has increased significantly in most industrialized countries. This is illustrated by a strong upwards trend in the percentage of citizens who, according to the Eurobarometer survey, believes that environmental issues are "very important" (see Table 1). ${ }^{1}$ In addition, the number of organized environmentalists has increased and at least fourteen new international environmental lobby groups were founded during the same period [Frijof-Nansen-Institute (1994)]. The further up-spring of green political parties and the adaptation of environmental policy in the policy platforms of most traditional political parties, let us safely conclude that a rise of environmentalism has occurred.

Table 1: The Development of Environmental Awareness in Europe, 1974-96: The percentage of respondents to the Eurobarometer survey who believes that environmental issues are very important.

\begin{tabular}{|c|c|c|c|c|c|c|c|c|}
\hline year & 1974 & 1975 & 1976 & 1981 & 1983 & 1988 & 1992 & 1996 \\
\hline$\%$ & 42 & 46 & 57 & 60 & 60 & 84 & 85 & 83 \\
\hline
\end{tabular}

The impact of a rise of environmentalism on environmental policy is complex. It depends on the political behavior of environmentalists and other politically active groups as well as on the institutional structures within which political and economic competition take place. The political strategy of environmentalists is a function of the interaction between environmental policy, transnational pollution and international trade. To see why, consider the following example. Two countries, $A$ and $B$, trade with each other. Production generates pollution that is deposited in both countries. Let country $A$ impose a tax on pollution emitted from firms within its jurisdiction. This gives firms in country $B$ a comparative advantage relative to firms in country $A$. The induced reallocation of production reduces pollution in country $A$ but

\footnotetext{
${ }^{1}$ See Eurostat (1974-96).
} 
increases pollution in country $B$. Environmentalists in country $A$ anticipate these effects. Accordingly, whether or not they support the increase in the tax depends on how they value environmental quality abroad relative to environmental quality at home. When they care a lot about pollution abroad, they may, to prevent pollution abroad from increasing, oppose the increase in the pollution tax. When they do not care much about pollution abroad, they support the increase in the pollution tax.

The purpose of this paper is to develop a political economy model of environmental policy to clarify the link between a rise of environmentalism, international trade and transnational pollution. The main contribution of the paper is to identify - within the class of reciprocal externality problems - the circumstances under which a rise of environmentalism leads to stricter environmental policy and less pollution and to point out that environmental awareness is not a guarantee for high environmental standards. In particular, it is shown that the impact of environmentalism on pollution depends on i) the extent to which pollution is internationally mobile and ii) the extent to which environmentalists care about pollution in other countries. In situations where pollution is immobile and environmentalists care a lot about pollution in other countries, a rise of environmentalism can be environmentally harmful and lead to more, rather than to less, total pollution. Data for sulfur emission in Europe and North America show that several countries, including Canada, Turkey, Russia, Romania, France and Germany satisfy the (necessary) condition for this to happen.

The rise of environmentalism is primarily a phenomenon observed in industrialized countries. Therefore, our model focuses on the interaction between two industrialized countries. The two countries engage in regional trade and the underlying environmental problem is "reciprocal" in the sense that emission from one country is partly deposited in other countries in the region. An example of this type of problem is that of sulfur emission and acid rain [Newbery (1990) and Murdoch, Sandler, and Sargent (1997)]. We focus on pollution taxes as the key environmental regulation instrument. This is motivated by the recent interest in $\mathrm{SO}_{2}$ and other pollution taxes in countries such as Denmark, Belgium, France, Norway, Poland, the UK, Germany and Sweden [ OECD (1998)].

Our model has three key features which capture what we believe to be essential aspects of the situation. First, international trade is of the intraindustry type. This is reasonable as the lion's share of trade among industrialized countries is of this type and it motivates our adoption of the reciprocal 
dumping model [Brander (1981)]. Moreover, to isolate the impact of a rise of environmentalism on environmental policy from that of changes in trade policy [Copeland and Taylor (1994), Bommer (1996)], we assume that trade policy is exogenously given and, for simplicity, consider a situation with free trade.

Second, environmental policy is endogenous and so, the rise of environmentalism affects the economy via a change in environmental policy. For this purpose, we adopt the political economy approach. A central idea of this approach to environmental regulation is that environmental policy is determined by competition among special-interest groups trying to influence the decisions of electorally motivated politicians. ${ }^{2}$ The key organized interests in the context of environmental policy are polluters and environmentalists. ${ }^{3}$ Polluters are typically represented by producer lobby groups such as trade and professional associations and are mainly concerned with the impact of environmental taxation on profit. Environmentalists are represented by green lobby groups such as the World Wildlife Foundation, Friends of the Earth, Greenpeace and many other NGOs and are mainly concerned with environmental protection. ${ }^{4}$ To model the interaction between the government and the two lobby groups, we adopt the common agency approach used by Bernheim and Whinston (1986), Grossman and Helpman (1994) and many others. It is based on the idea that the lobby groups contribute to the government's election campaign to gain influence on economic policy. While the focus on campaign contributions rules out explicit consideration of a range of other influence activities such as provision of decision-relevant information aimed at voters, politicians or bureaucrats, the common agency model captures well the idea that equilibrium policy reflects a trade-off between the interests of different organized groups (and social welfare) and it is, therefore, as a first approximation, appropriate for our purpose.

Third, environmentalists are concerned with two aspects of environmental damage. First, they are, as all other citizens, concerned with the environmental damage actually inflicted upon them by pollution. Second, following Hillman and Ursprung (1992) and Hoekman and Leidy (1992), they are con-

\footnotetext{
${ }^{2}$ See, e.g., Buchanan and Tullock (1975), Hoekman and Leidy (1992), Hillman and Ursprung (1992), Fredriksson (1997), Aidt (1998b) and Svendsen (1998).

${ }^{3}$ See Svendsen (1998) and Dijkstra (1998) for studies of environmental lobbying in the US and Holland, respectively.

${ }^{4}$ See Marshall (1998) for a survey of the attitude of a large number of UK interest groups and firms to environmental regulation.
} 
cerned with the (perceived) environmental damage inflicted upon citizens in the foreign country. This assumption is motivated by the fact that environmentalists often take a comprehensive view on environmental problems that goes beyond narrow self-interest. One example of this is the Tuna-Dolphin problem in the Eastern Tropical Pacific Ocean, where primarily American environmentalists for decades have argued in favor of a ban on killing Dolphins and other marine mammals [Kober (1998)]. The idea that environmentalists have this extended environmental concern plays an important role in our model. In particular, we model the rise of environmentalism as an increase in the number (organized) environmentalists. Accordingly, a rise of environmentalism gives more weight in the political trade-off to the consequences of pollution at home and abroad.

Our paper is related to a number of branches of the literature on environment and trade. First, the link between environmental quality and income is empirically well documented [Grossman and Krueger (1995) and Hilton and Levinson (1998)]. For many pollutants there is a tendency for pollution levels to rise initially, peak and then decline with income. The rise of environmentalism is likely to be related to income growth and so, our model indirectly contributes to a better understanding of the link between income, environmental policy and environmental quality. A closely related literature focuses on the relationship between trade liberalizations and environmental quality. As pointed out by Copeland and Taylor (1994) and Antweiler, Copeland, and Taylor (1998), the income gains associated with trade liberalization can lead to a political demand for tougher environmental policy thereby counteracting the scale effect (more output and pollution being produced) and the composition effect (expansion of polluting sectors) associated with trade liberalization and possibility reduce pollution levels. Bommer (1996) makes a related point in his study of trade liberalization in the EU. He shows that environmental and trade policy are substituting tools for redistribution and that a trade liberalization therefore can lead to stricter environmental policy. Our model complements these studies by focusing on environmentalism as the driving force behind endogenous changes in environmental policy.

Second, since changes in trade patterns have environmental consequences, environmentalists have an interest in trade policy. Hillman and Ursprung: (1992) show that the stake of environmentalists in trade policy depends on their concern about environmental damage in other countries. Our model complements this study by focusing on the feedback from changes in trade and emission patterns to endogenous environmental policy for given trade 
policy.

The rest of the paper is organized as follows. In section 2, we present the model. In section 3 , we characterize environmental policy in national political equilibrium. In section 4, we analyze the implications of a rise of environmentalism and derive the main results. In section 5, we discuss extensions of the model. Finally, in section 6 , we conclude.

\section{The Model}

\subsection{The Economic Model}

The model has two countries, indexed $j=A, B$. Each country has three types of citizens: consumers $(\mathrm{C})$, environmentalists $(\mathrm{E})$ and capitalists $(\mathrm{P})$. The size of the population in each country is normalized to one. All citizens have the same preferences with respect to goods but differ with respect to source of income and environmental preference. The utility function is assumed to be quasi-linear and additively separable in consumption of goods and actual environmental damage:

$$
U_{j}=u_{j}\left(C_{x}^{j}\right)+C_{y}^{j}-\beta_{j} \frac{E_{j}^{2}}{2}
$$

where $C_{x}^{j}$ is consumption of good $x$ and $C_{y}^{j}$ is consumption of a numeraire good $y$. We assume that $u_{j}^{\prime}>0, u_{j}^{\prime \prime}<0$ and $\beta_{j}>0$. The term $\beta_{j} \frac{E_{j}^{2}}{2}$ represents actual environmental damage inflicted upon a representative citizen of country $j$. It is increasing in the amount of pollution deposited within the borders of the relevant country, $E_{j}$, at an increasing rate. ${ }^{5}$ Notice that all citizens irrespectively of type suffer from degeneration of the physical environment in the country where they live.

As argued by Hoekman and Leidy (1992) and Hillman and Ursprung (1992), environmentalists are concerned about pollution in foreign countries for moral or altruistic reasons. The extended environmental concern implies that environmentalists care about the impact of domestic environmental policy on environmental damage (as they perceive it) in the neighboring

\footnotetext{
${ }^{5}$ Increasing marginal damage is a reasonable assumption for most environmental problems, including $\mathrm{SO}_{2}$ air pollution. Nevertheless, it is possible to find examples in which, after some point, marginal environmental damage is decreasing [see, e.g., the Cuyahoga River example discussed in Schleich (1999)].
} 
country. For example, environmentalists in Britain are, typically, concerned with acidification of lakes and soil, forest death and other consequences of $\mathrm{SO}_{2}$ emission, not only in Britain but also in, for example, Scandinavia. To capture this idea, we assume that the utility function of a representative environmentalist is given as follows:

$$
U_{j}^{E}=U_{j}-\delta_{j} \frac{E_{-j}^{2}}{2}, \quad \delta_{j}>0
$$

where $\delta_{j} \frac{E_{-j}^{2}}{2}$ represents environmental damage in the neighboring country as perceived by non-resident environmentalists.

Consumers, environmentalists and capitalists have two common sources of income. First, they receive wage income, $w_{j}$, from inelastic supply of (one unit of) labor to the national labor market. Second, they receive a lump sum transfer, $R_{j}($.$) . The transfer is financed by the revenue from the pollution tax$ $\left(t_{j}\right)$ levied on the firm located within the relevant jurisdiction. In addition to this, capitalists have a third source of income. They earn income from the shares they hold in the domestic firm. From utility maximization subject to given income, $I_{j}^{i}$, we derive the (aggregated) demand function for good $x$ as $d_{x}^{j}\left(p_{j}\right)$, where $p_{j}$ is the relative domestic price of $x .{ }^{6}$ Inverse demand is $p_{j}=p_{j}\left(C_{x}^{j}\right)$ with $p_{j}^{\prime}<0$. Consumer's surplus from consumption of good $x$ is $C S_{j}\left(p_{j}\right)=u_{j}\left(d_{x}^{j}\left(p_{j}\right)\right)-p_{j} d_{x}^{j}\left(p_{j}\right)$. Accordingly, the (derived) indirect utility function of a representative member of group $i=P, C, E$ is

$$
v_{j}^{i}\left(p_{j}, I_{j}^{i}, E_{j}, E_{-j}\right)=I_{j}^{i}+C S_{j}\left(p_{j}\right)-\beta_{j} \frac{E_{j}^{2}}{2}-\tau \delta_{j} \frac{E_{-j}^{2}}{2},
$$

where $\tau$ is an indicator variable equal to one if $i=E$ and zero otherwise. Consumer's surplus is decreasing in the domestic price of good $x$.

The two goods, $x$ and $y$, are produced in both countries and are internationally traded. While there are no transportation costs or other barriers to trade, we assume that the cost of relocating firms is prohibitive.

The $y$-good is produced in a perfectly competitive sector with CRS technology and labor as the only input. Normalizing the international price of

\footnotetext{
${ }^{6}$ Let $I_{j}$ denote the national income of country $j$. Then the demand for the numeraire good is $I_{j}-d_{x}^{j}\left(p_{j}\right)$. We assume this is positive for all relevant $p_{j}$. Notice that environmental damage is taken as given when the consumption choice is made and that individual demand is equal to aggregate demand because of the normalization of the size of the population to one.
} 
$y$ to 1 , this implies that the national wage rate is 1 in both sectors as labor is assumed to be mobile domestically. The $x$-good is produced under conditions of imperfect competition and each country has one firm that produces the good. ${ }^{7}$ Firm $A$ produces $x_{A}=x_{A A}+x_{A B}$, where $x_{A A}$ is supplied to the domestic market and $x_{A B}$ is exported to the foreign market. ${ }^{8}$ Likewise, firm $B$ produces $x_{B}=x_{B B}+x_{B A}$. The production technology is given by $l_{j}^{x}=F+c_{j} x_{j}$, where $F$ a fixed labor requirement to start up production and $c_{j}$ is the labor requirement per unit of output. Since the wage rate is 1 , we can write the cost function as $C_{j}\left(x_{j}\right)=w l_{j}^{x}=F+c_{j} x_{j}$, where we set $F$ equal to zero. The two firms consider the two markets as segmented. Hence, the equilibrium condition at market $j$ is: $C_{x}^{j}=x_{A j}+x_{B j}, j=A, B$.

Production of $x$ (but not $y$ ) pollutes the environment. We assume that emission, $e_{j}$, from firm $j$ is proportional to the level of production. In particular, ${ }^{9}$

$$
e_{j}=x_{j}, \quad j=A, B .
$$

Pollution is transnational. Let $\alpha_{l j}$ be the proportion of emission from firm $l$ that is deposited within the borders of country $j, l=A, B, j=A, B$. Pollution deposited in country $j$ can then be defined as $E_{j}=\alpha_{A j} e_{A}+\alpha_{B j} e_{B}$, $j=A, B$. We focus on a reciprocal externality problem (such as $\mathrm{SO}_{2}$ pollution and acid rain). Accordingly, pollution is partly deposited outside the source country, i.e., $\alpha_{l j}>0$ for all $l, j$ and $\alpha_{j A}+\alpha_{j B}=1, j=A, B$. Notice, however, that this specification is rich enough to capture many other types of externalities (see section 5).

Total profit of firm $j$ is:

$$
\begin{aligned}
\pi_{j}= & p_{A}\left(x_{A A}+x_{B A}\right) x_{j A}+p_{B}\left(x_{B B}+x_{A B}\right) x_{j B}- \\
& c_{j} x_{j}-t_{j} e_{j},
\end{aligned}
$$

\footnotetext{
${ }^{7}$ See Barrett (1994b), Ulph (1997) and Rauscher (1997) for a discussion of trade models with imperfectly competitive markets applied to international environmental problems. The basic structure of the model is that of Brander and Spence (1984).

${ }^{8}$ We use the convention that the first index refers to the source and the second index refers to the destination.

${ }^{9}$ This is obviously a great simplification. Firms have different pollution technologies and can invest in abatement, which reduces emission per unit of output. However, as long as pollution technologies are not too different and abatement and production decisions are made simultaneously, introducing different unit emission coefficients and allowing firms to invest in abatement effort do not affect the nature of our results [Aidt (1998a)].
} 
where $t_{j}$ is the pollution tax imposed by government $j$. The two firms have Cournot conjectures. We assume that the Nash equilibrium in each market is unique and stable. The profit function of firm $j$ is a function of the pollution taxes imposed in the two countries: $\pi_{j}^{*}=\pi_{j}\left(t_{A}, t_{B}\right)$.

\subsection{The Political Model}

We focus on the political economy of pollution taxation in country $A$ and assume that $t_{B}$ is exogenously given. This is motivated by the fact that environmentalists often advocate that governments should go ahead unilaterally and enforce high environmental standards within their jurisdiction [Hoel (1991)] and that the most fierce opposition from producer interests to pollution taxation arises precisely in that context. The assumption, however, also rules out strategic aspect of pollution taxation. This is harder to justify but fortunately the main result is unaffected by the simplification (see section 5 ).

Let the proportion of capitalists be $\bar{\gamma}_{A}^{P}$, the proportion of consumers be $\bar{\gamma}_{A}^{C}$ and the proportion of environmentalists be $\bar{\gamma}_{A}^{E}$. The government in country $A$ can tax pollution emitted by firm $A$. It is concerned with reelection in an upcoming but un-modeled election. ${ }^{10}$ In the absence of lobbying, it cares about social welfare defined as:

$$
W_{A}=w_{A}+\pi_{A}(.)+R_{A}(.)+C S_{A}(.)-\beta_{A} \frac{E_{A}^{2}}{2}-\bar{\gamma}_{A}^{E} \delta_{A} \frac{E_{B}^{2}}{2},
$$

where we have used the fact that $\bar{\gamma}_{A}^{E}+\bar{\gamma}_{A}^{P}+\bar{\gamma}_{A}^{C}=1$ and that each capitalist has profit income $\frac{\pi_{A}(.)}{\bar{\gamma}_{A}^{P}}$.

Since money are needed to run an effective election campaign, the government is willing to deviate from the social welfare maximizing policy if (domestic) lobby groups offer campaign contributions. Let $M_{A}^{k}\left(t_{A}\right)$ be the contribution from lobby group $k$ when the policy is $t_{A}$. The payoff function of the government is:

$$
v_{A}^{G}=\theta_{A} W_{A}\left(t_{A}\right)+\sum_{k} M_{A}^{k}\left(t_{A}\right),
$$

where $\theta_{A}>0$ is the relative weight given to social welfare.

\footnotetext{
${ }^{10}$ This is the standard assumption in the literature see, for example, Grossman and Helpman (1994). Grossman and Helpman (1996) model the election explicitly.
} 
Two lobby groups are active in country $A$. Some of the environmentalists organize a green lobby group and some of the capitalists organize a producer lobby group. Consumers are unable to overcome the free rider problem and do not organize a consumer lobby group. ${ }^{11}$ We assume that only environmentalists can be members of the green lobby group and that only capitalists can be members of the producer lobby group. The proportion of organized environmentalists is $\gamma_{A}^{E} \leq \bar{\gamma}_{A}^{E}$ and the proportion of organized capitalists is $\gamma_{A}^{P} \leq \bar{\gamma}_{A}^{P}$.

In contrast to Grossman and Helpman (1994) and others, we assume that the two lobby groups are functionally specialized. A lobby group is functionally specialized if it advocates one particular aspect of the underlying issue only, disregarding other dimensions about which the members care. The motivation for focusing on functionally specialized lobby groups is empirical. While it is possible to find examples of lobby groups with multiple goals [Aidt (1998b)], the survey of interest group attitude in Marshall (1998) clearly demonstrates that many lobby groups are highly specialized.

The producer lobby group is concerned with the impact of $t_{A}$ on the international competitiveness of the domestic firm and its objective is to protect the profit income of its members. Its gross payoff function is:

$$
v_{A}^{P}=\frac{\gamma_{A}^{P}}{\bar{\gamma}_{A}^{P}} \pi_{A}\left(t_{A}\right)
$$

Its policy preference depends on the impact of $t_{A}$ on profit. We find that ${ }^{12}$

Proposition 1 The producer lobby group always supports a decrease in the pollution tax, i.e.,

$$
\frac{\partial v_{A}^{P}}{\partial t_{A}}=\frac{\gamma_{A}^{P}}{\bar{\gamma}_{A}^{P}} \frac{\partial \pi_{A}}{\partial t_{A}}<0
$$

\footnotetext{
${ }^{11}$ Lobbying is subject to a collective action problem [Olson (1965)]. We implicitly assume that some citizens can overcome this problem, while others cannot. This can be justified as follows. The firm is owned by a small number of capitalists, which makes it easier to control free riding. Environmentalists are likely to be more numerous. However, since they are particular committed to the environmental cause, it is conceivable that they possess the necessary social skills to organize a lobby group. Finally, consumers are numerous and without a strong commitment to political action. Hence, they are unlikely to organize a lobby group.

${ }^{12} \mathrm{~A}$ proof is available upon request.
} 
This result reflects the well-known profit shifting effect whereby an increase in $t_{A}$ reduces the competitiveness of firm $A$ and shifts profit and production abroad [Brander and Spencer (1985)].13

The green lobby group focuses on environmental protection and is concerned with actual environmental damage at home and perceived environmental damage abroad. Its gross payoff function is:

$$
v_{A}^{E}=-\frac{1}{2} \gamma_{A}^{E}\left[\beta_{A} E_{A}^{2}+\delta_{A} E_{B}^{2}\right] .
$$

The policy preference of the green lobby group is determined by

$$
\frac{\partial v_{A}^{E}}{\partial t_{A}}=-\gamma_{A}^{E}\left(\beta_{A} E_{A} \frac{\partial E_{A}}{\partial t_{A}}+\delta_{A} E_{B} \frac{\partial E_{B}}{\partial t_{A}}\right)
$$

and depends, among other things, on the impact of $t_{A}$ on domestic and foreign pollution levels.

To see how the pollution tax affects pollution in the two countries, consider an increase in $t_{A}$. This provides firm $A$ with an incentive to reduce emission $\left(\frac{\partial e_{A}}{\partial t_{A}}<0\right)$ and, as a result, production is scaled down. This, in turn, provides firm $B$ with a strategic incentive to expand production. As a consequence, firm $B$ emits more pollution $\left(\frac{\partial e_{B}}{\partial t_{A}}>0\right)$. This tends to counteract the initial reduction of emission from firm $A$. The net effect of an increase in $t_{A}$ is, however, unambiguous: total pollution, $E=e_{A}+e_{B}$, is reduced, i.e., $\frac{\partial E}{\partial t_{A}}<0 .{ }^{14,15}$ The distribution of the reduction of total pollution between the

\footnotetext{
${ }^{13}$ The orthodox view that environmental regulation has an adverse impact on international competitiveness has recently been challenged. Revisionists, such as Porter (1994), argue that environmental regulation, on the contrary, has a positive impact on international competitiveness and in a recent survey of the empirical literature on the environment-competitiveness linkage in the US, Jaffe, Peterson, Portney, and Stavins (1995) conclude that "although the long-run social costs of environmental regulation may be significant, studies attempting to measure the effect of environmental regulation on net exports, overall trade flows, and plant-location decisions have produced estimates that are either small, statistically insignificant, or not robust to tests of model specification" ( $p$. 157-58). However, as pointed out by Rauscher (1997), these empirical findings could be attributed to measurement problems associated with quantifying and comparing environmental legislation in different countries.

${ }^{14}$ The details of the calculations are available upon request.

${ }^{15}$ The result is similar to the result from strategic trade policy that, under Cournot Conjectures, an export subsidy increases the output of the recipient firm more than it reduces the output of the foreign rival [Brander and Spencer (1985)].
} 


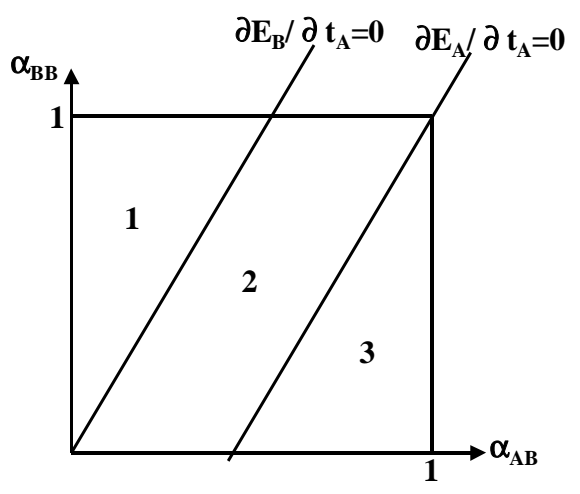

Figure 1: The three scenarios

two countries depends on pollution mobility as well as on the size of $\frac{\partial e_{B}}{\partial t_{A}}$ and $\frac{\partial e_{A}}{\partial t_{A}}:$

$$
\begin{aligned}
& \frac{\partial E_{A}}{\partial t_{A}}=\left(\alpha_{B A}-\eta_{A} \alpha_{A A}\right) \frac{\partial e_{B}}{\partial t_{A}}, \\
& \frac{\partial E_{B}}{\partial t_{A}}=\left(\alpha_{B B}-\eta_{A} \alpha_{A B}\right) \frac{\partial e_{B}}{\partial t_{A}},
\end{aligned}
$$

where $\eta_{A}=-\frac{\partial e_{A}}{\partial t_{A}} / \frac{\partial e_{B}}{\partial t_{A}}>1\left(\right.$ as $\left.\frac{\partial E}{\partial t_{A}}<0\right)$. Due to linear dependency between the transport coefficients $\left(\alpha_{j A}+\alpha_{j B}=1\right)$, equations (12) and (13) give rise to three, rather than four, scenarios. For given $t_{A}$, these are illustrated in Figure $1 .^{16}$

Based on data for sulphur emission in Europe and the US, it appears, however, that only two of the three scenarios are empirically relevant (see Appendix). Most European countries and the US meet the conditions of scenario $2\left(\frac{\partial E_{A}}{\partial t_{A}}<0\right.$ and $\left.\frac{\partial E_{B}}{\partial t_{A}}<0\right)$. Countries like Canada, Russia, Ukraine,

\footnotetext{
${ }^{16}$ For given $t_{A}, \eta_{A}$ can be treated as a constant. The larger $\eta_{A}$ is, the larger is area 2 relative to the other areas. Hence, when $\eta_{A}$ goes to infinity scenario 1 and 3 disappear.
} 
Turkey, Romania, Spain, Finland, the UK, Germany and others meet (for $\left.\eta_{A}=1.5\right)$ the conditions of scenario $1\left(\frac{\partial E_{A}}{\partial t_{A}}<0\right.$ and $\left.\frac{\partial E_{B}}{\partial t_{A}}>0\right)$. Non of the 38 countries considered, however, meets the conditions of scenario $3\left(\frac{\partial E_{A}}{\partial t_{A}}>0\right.$ and $\left.\frac{\partial E_{B}}{\partial t_{A}}<0\right)$. For this reason, we focus in the following on scenario 1 and 2 only.

Scenario 1, in which $\frac{\partial E_{A}}{\partial t_{A}}<0$ and $\frac{\partial E_{B}}{\partial t_{A}}>0$, arises when pollution is immobile. In this case, pollution, by and large, stays at home. The increase in emission from firm $B$, therefore, deteriorates the environment in country $B$, while the reduction in emission from firm $A$ benefits the environment in country $A$. The key point is that pollution can be imported and/or exported via reallocation of production between firms in the two countries. Similar effects have previously been discussed by, for example, Pethig (1976), Siebert, Eichberger, Gronych, and Pething (1980) and Rauscher (1997). Scenario 2, in which $\frac{\partial E_{A}}{\partial t_{A}}<0$ and $\frac{\partial E_{B}}{\partial t_{A}}<0$, arises when pollution is mobile. In this case, an increase in $t_{A}$ reduces environmental damage in both countries.

We can now characterize more precisely the policy preference of the green lobby group:

Proposition 2 The green lobby group supports a reduction in $t_{A}$ if

$$
\frac{\beta_{A}}{\delta_{A}} \leq-\frac{E_{B}}{E_{A}} \frac{\left(\alpha_{B B}-\eta_{A} \alpha_{A B}\right)}{\left(\alpha_{B A}-\eta_{A} \alpha_{A A}\right)} \equiv K\left(t_{A}\right)
$$

and supports an increase in $t_{A}$ otherwise.

Proof. Condition (14) follows from simple manipulations of equation (11) using equations (12) and (13)

Notice that the left hand side of condition (14), denoted $K\left(t_{A}\right)$, is a function of $t_{A}$. The green lobby group supports a reduction in the pollution tax when condition (14) is satisfied. This requires two things. First, a necessary but not sufficient condition is that pollution is immobile (scenario 1), as $\frac{\partial E_{B}}{\partial t_{A}}>0$ and $\frac{\partial E_{A}}{\partial t_{A}}<0$ implies that $K\left(t_{A}\right)>0$. Second, a sufficient condition is that the actual marginal environmental damage at home is low compared to perceived marginal environmental damage abroad (i.e., $\beta_{A} / \delta_{A} \leq K\left(t_{A}\right)$ ). Under these circumstances, the trade-off between actual environmental damage at home $\left(\frac{\partial E_{A}}{\partial t_{A}}<0\right)$ and perceived environmental damage abroad $\left(\frac{\partial E_{B}}{\partial t_{A}}>0\right)$ is such that the green lobby group supports a low pollution tax in country $A$ as that is what it takes to reduce environmental 
damage in country $B$. When, on the other hand, pollution is physically mobile as in scenario 2 where $\frac{\partial E_{B}}{\partial t_{A}}<0$ or pollution is physically immobile as in scenario 1 but $\beta_{A} / \delta_{A}>K\left(t_{A}\right)$, the green lobby group supports an increase in the pollution tax. We notice the importance of the environmentalists' extended environmental concern. If this concern is absence $\left(\delta_{A}=0\right)$, the green lobby group surely supports an increase in $t_{A}$.

\section{Environmental Policy in National Political Equilibrium}

The pollution tax in country $A$ is determined by political pressure from the two lobby groups. Following Bernheim and Whinston (1986), Grossman and Helpman (1994) and many others ${ }^{17}$, the two lobby groups (the principals) move first and simultaneously offer the government (the agent) contribution schedules that specify the payment to be made to the government's election campaign as a function of the pollution tax. Taking the contribution schedules and the economic behavior of the private section as given, the government moves second and implements the politically optimal pollution tax. After the pollution tax has been imposed, the private sector adjusts to the new policy circumstances and the lobby groups contribute to the government's election campaign as promised.

A national political equilibrium is defined as a subgame perfect equilibrium of this multi-stage game. Assuming that the contribution schedules are differentiable, it can be shown that the politically optimal tax satisfy the following condition: ${ }^{18}$

$$
\begin{aligned}
\Lambda_{A}\left(t_{A}^{P O}\right)= & \theta_{A} \frac{\partial W_{A}}{\partial t_{A}}+\frac{\gamma_{A}^{P}}{\bar{\gamma}_{A}^{P}} \frac{\partial \pi_{A}}{\partial t_{A}} \\
& -\gamma_{A}^{E}\left(\beta_{A} E_{A} \frac{\partial E_{A}}{\partial t_{A}}+\delta_{A} E_{B} \frac{\partial E_{B}}{\partial t_{A}}\right) \\
= & 0,
\end{aligned}
$$

\footnotetext{
${ }^{17}$ See, for example, Dixit (1996), Dixit, Grossman, and Helpman (1997), Fredriksson (1997), Aidt (1998b) and Schleich (1999).

${ }^{18}$ For details on how to solve the common agency game, see Aidt (1998a) or Grossman and Helpman (1994).
} 
where

$$
\frac{\partial W_{A}}{\partial t_{A}}(.)=\theta_{A}\left(\frac{\partial C S_{A}}{\partial t_{A}}+\frac{\partial R_{A}}{\partial t_{A}}+\frac{\partial \pi_{A}}{\partial t_{A}}-\beta_{A} E_{A} \frac{\partial E_{A}}{\partial t_{A}}-\bar{\gamma}_{A}^{E} \delta_{A} E_{B} \frac{\partial E_{B}}{\partial t_{A}}\right) .
$$

For ease of reference, we denote the right hand side of equation $(15)$ by $\Lambda_{A}($.$) .$ We assume that $\frac{\partial \Lambda_{A}(.)}{\partial t_{A}}<0 .{ }^{19}$ Condition (15) shows that the politically optimal pollution tax maximizes a weighed sum of the gross welfare of the government and the two lobby groups.

In the absence of lobbying, the government implements the pollution tax that maximizes social welfare (given by the solution to $\frac{\partial W_{A}}{\partial t_{A}}()=$.0 in equation (16)). In the presence of lobbying, the politically optimal tax is, in general, different from the socially optimal one. This is because the two lobby groups are successful in buying concessions (see equation (15)). The producer lobby group always rewards the government for a reduction in the pollution tax below $t_{A}^{S O}$ (Proposition 1). The lobbying strategic of the green lobby group is more complex (Proposition 2) and two situations can arise. First, when the green lobby group rewards the government for an increase in the pollution tax above $t_{A}^{S O}\left(\beta_{A} / \delta_{A}>K\left(t_{A}^{S O}\right)\right)$, the interests of the two groups are pitched against each other and the deviation from the socially optimal tax depends on the relative political power of the two groups. If, for example, the green lobby group represents only a tiny fraction of environmentalists $\left(\gamma_{A}^{E} \rightarrow 0\right)$, then, ceteris paribus, the politically optimal tax is below the socially optimal one and vice versa if the producer lobby group represents only a tiny fraction of capitalists $\left(\gamma_{A}^{P} \rightarrow 0\right)$. Second, when the green lobby group rewards the government for a reduction in the pollution tax below $t_{A}^{S O}$ $\left(\beta_{A} / \delta_{A} \leq K\left(t_{A}^{S O}\right)\right)$, the interests of the two lobby groups converge and an environmentally unfriendly "coalition" of capitalists and environmentalists emerge. The result being a reduction in the politically optimal pollution tax below $t_{A}^{S O}$ independently of the relative political power of the two groups. This happens when pollution is immobile and environmentalists care a lot about environmental damage in the other country.

\footnotetext{
${ }^{19}$ This assumption implies that the relevant second order conditions are satisfied. A discussion of the conditions under which this is true is available upon request.
} 


\section{A Rise of Environmentalism, Pollution Tax- ation and Environmental Quality}

Having characterized the national political equilibrium, we analyze how the equilibrium is affected by a rise of environmentalism. Two interpretations of the phenomenon can be given within the context of our model. First, environmentalism is rising when the proportion of environmentalists in the population increases. This corresponds to a shift in the preference structure. Citizens, who were previously only concerned with the damage they themselves were suffering, become (or are replaced by citizens, who are) concerned with the perceived environmental damage occurring outside their own country of residence. This shift can, for instance, be induced by assimilation of information about the costs of pollution in other countries. Empirical observations suggest that this was indeed the case during the 1970s and 1980s where the damage associated with acid rain and many other international environmental problems became known to most people. Second, environmentalism is rising when the green lobby group recruits new members among unorganized environmentalists. This corresponds to a change in underlying political structures. This portraits the observed political mobilization of environmentalists in the $1970 \mathrm{~s}$ and $1980 \mathrm{~s}$. Both interpretations are consistent with the idea that income growth is an important source of environmental awareness. In particular, with environmental protection being a normal good, it is not surprising that the voice of environmentalists has become stronger in most industrialized countries over the past decades. ${ }^{20}$ Moreover, the two interpretations give rise to similar theoretical predictions so below it is sufficient to focus on the case of a rise of organized environmentalism.

\subsection{An Increase in the Proportion of Organized Envi- ronmentalists}

To derive the impact of a rise of environmentalism, represented by an increasing in the proportion of organized environmentalists $\left(d \gamma_{A}^{E}>0\right)$, on $t_{A}^{P O}$, we total differentiate equation (15) to obtain

\footnotetext{
${ }^{20}$ See Grossman and Krueger (1995) and Hilton and Levinson (1998) for recent studies that investigate the link between income gains, environmental quality and environmental policy.
} 


$$
\frac{d t_{A}^{P O}}{d \gamma_{A}^{E}}=-\frac{\frac{\partial \Lambda_{A}}{\partial \gamma_{A}}}{\frac{\partial \Lambda_{A}}{\partial t_{A}}} .
$$

As $\frac{\partial \Lambda_{A}}{\partial t_{A}}<0$, the sign of $\frac{\partial \Lambda_{A}}{\partial \gamma_{A}^{E}}$ determines the impact on the pollution tax. We find that

$$
\frac{\partial \Lambda_{A}}{\partial \gamma_{A}^{E}}=\frac{1}{\gamma_{A}^{E}} \frac{\partial v_{A}^{E}}{\partial t_{A}}\left(t_{A}^{P O}\right) .
$$

As the membership of the green lobby group increases, the group is willing, at the margin, to contribute more money to the government's election campaign. The government appreciates this and adjusts the pollution tax to please the green lobby group. The adjustment depends on the lobbying strategy of the green lobby as characterized by Proposition 2. The key results are summarized in Table 2.

Table 2: The impact of a rise of environmentalism on the pollution tax $\left(t_{A}\right)$ and pollution patterns.

\begin{tabular}{|c|c|c|c|}
\hline Mobility of Pollution & Immobile & Immobile & Mobile \\
\hline$\beta_{A} / \delta_{A} \leq K\left(t_{A}^{P O}\right)$ & Not satisfied & Satisfied & Not sastisfied \\
\hline$t_{A}$ & up & down & up \\
\hline$E_{A}$ & down & up & down \\
\hline$E_{B}$ & up & down & down \\
\hline$E=E_{A}+E_{B}$ & down & up & down \\
\hline
\end{tabular}

A rise of environmentalism can have paradoxical effects. When pollution is physically immobile (scenario 1 ) and environmentalists are sufficiently concerned with foreign environmental damage $\left(\beta_{A} / \delta_{A} \leq K\left(t_{A}^{P O}\right)\right)$, the green lobby group uses its additional political influence to reward the government for a reduction in $t_{A}$. This reduces pollution in country $B$ but increases pollution in country $A$. The net effect being an increase in world-wide pollution. When the green lobby group is mainly concerned with domestic environmental damage $\left(\beta_{A} / \delta_{A}>K\left(t_{A}^{P O}\right)\right)$, the impact becomes less paradoxical. Pollution at home is reduced but at the expense of more pollution abroad and we have situation where a rise of environmentalism in one country imposes additional environmental costs on the other country. When pollution 
is mobile (scenario 2), the paradox disappears altogether as the green lobby group uses its additional influence to increase the pollution tax resulting in a reduction of pollution in both countries.

\section{Extensions of the Model}

\subsection{Alternative Externality Problems}

Above we focussed on reciprocal environmental problems. While the importance of $\mathrm{SO}_{2}$ air pollution and other reciprocal problems justify this focus, problems associated with unidirectional and global externalities also arise in the international context and it is of interest to see if a rise of environmentalism can help internalize these externalities.

\subsubsection{A Unidirectional Externality Problem}

Some important environmental problems, including pollution of river systems and deforesting, are unidirectional; that is, emission from up-stream countries is deposited in down-stream countries without any (significant) reverse emission flows. Let country $A$ be located up-stream from country $B$. Assume that all pollution is deposited down-stream, i.e., $\alpha_{A A}=\alpha_{B A}=0$ and $\alpha_{B B}=\alpha_{A B}=1$. An increase in the proportion of either unorganized or organized environmentalists in country $A$ increases $t_{A}$. From equations (12) and (13), it follows that an increase in the pollution tax in country $A$ always reduces pollution in country $B$. Accordingly, increasing environmental awareness up-stream has a beneficial impact on the environment down-stream.

\subsubsection{A Global Externality Problem}

A global environmental problem arises when the environmental effect on each country depends on the aggregate, world-wide level of pollution and not per se on each country's contribution to the total. Fxamples include the effect of emission of CFC on the ozone layer and the effect of emission of carbon dioxide and other greenhouse gasses on global warming. In these cases, actual and perceived environmental damage are functions of total emission, although the environmental damage endured by citizens in different countries may still be different. The recent discussion about and implementation of 
$\mathrm{CO}_{2}$ taxes in many European countries [OECD (1998)] makes it particularly interesting to analyze how a rise of environmentalism affects the political equilibrium of our model in the presence of a global externality problem.

When the externality is global, environmentalists face no conflict of interest: what is good for the environment at home is also (by definition) good for the environment abroad. ${ }^{21}$ Therefore, when a rise of environmentalism occurs, the environmentalists, organized or not, use their additional political influence to demand an increase in $t_{A}$. This reduces world-wide pollution to the benefit of citizens in both countries.

\subsection{Strategic Environmental Policy}

Above we assumed that the government of country $B$ did not react to the change in $t_{A}$ induced by the rise of environmentalism in country $A$. This made environmental policy non-strategic. The government in country $B$, however, has an incentive to respond to changes in $t_{A}$ [Barrett (1994b), Ulph (1997)]. The work by Murdoch, Sandler, and Sargent (1997) on sulphur and nitrogen oxides emission reductions in Europe suggests that strategic policy effects can be important. With Ulph (1998) as a notable exception, the political economy of strategic environmental policy has not been studied much in the literature and it is, therefore, of interest briefly to investigate the issue within our model. ${ }^{22}$

To this end, assume that the political structure of country $B$ is similar to that of country $A$. That is, the government of country $B$ is subject to lobbying from (local) capitalists and environmentalists and, in addition to campaign contributions, is concerned with (local) social welfare. The characterization of the politically optimal tax imposed in country $B$ is similar to the characterization of the politically optimal tax imposed in country $A$. Therefore, for given $t_{A}$, we can derive $t_{B}^{P O}$ from a condition, $\Lambda_{B}()=$.0 , similar to equation (15). We define an international political equilibrium as a Nash equilibrium in taxes rates, $\left(t_{A}^{P O^{*}}, t_{B}^{P O^{*}}\right)$, i.e.,

$$
\begin{aligned}
& \Lambda_{A}\left(t_{A}^{P O^{*}}, t_{B}^{P O^{*}}\right)=0 \\
& \Lambda_{B}\left(t_{A}^{P O^{*}}, t_{B}^{P O^{*}}\right)=0 .
\end{aligned}
$$

We assume that there is a unique and stable solution to these two equations.

\footnotetext{
${ }^{21}$ Formally, $\alpha_{A A}=\alpha_{B A}=\alpha_{A B}=\alpha_{B B}=1$.

${ }^{22}$ See Aidt (1998a) for more details.
} 
To disentangle the strategic policy effects of a rise of environmentalism, we need to consider two cases. First, consider the case in which tax rates are strategic complements. In this case, government $B$ mimics the policy change in country $A$ and so, the strategic interaction between the two governments reinforces the initial impact of the rise of environmentalism on the national political equilibrium in country $A$ (see section 4 ). For example, when government $A$ reduces $t_{A}$, government $B$ follows suit and a "race to the bottom" results with more world-wide pollution as the consequence. Second, consider the case in which tax rates are strategic substitutes. In this case, government $B$ counteracts the policy change in country $A$ and so, the strategic interaction between the two governments tend to moderate the environmental impact of the initial policy change in country $A$. For example, when government $A$ reduces $t_{A}$, government $B$ increases $t_{B}$, thereby preventing the "race to the bottom".

\subsection{International Coordination of Environmental Pol- icy}

Although it is known that cooperation among sovereign countries can be undermined by free-rider behavior [Carraro and Siniscalco (1992)] and that the subset of countries signing self-enforcing environmental agreements is small [Carraro and Siniscalco (1991); Barrett (1994a)], it is of interest to consider what would happen if the two governments could enter a binding international ( $\operatorname{tax})$ agreement. If so, the lobby groups could seek influence on the content of the agreement and thereby, de facto, gain influence on both domestic and foreign environmental policy. In particular, the green lobby group would use additional political influence to induce the local government to push (during the negotiations) for a high foreign pollution tax. While this reduces the likelihood that a rise of environmentalism causes counterproductive environmental effects, it cannot be ruled out that world-wide pollution increases [see Aidt (1998a)].

\section{Conclusion}

This paper develops a political economy model of environmental policy to clarify the link between a rise of environmentalism, international trade and 
transnational pollution. The main contribution of the paper is to identify the conditions under which an upward shift in environmental awareness and support to green lobby groups similar to that observed in many industrialized countries over the past decades can help internalize international environmental externalities via the political market for pollution taxes. We find that the impact of a rise of environmentalism depends on i) the extent to which pollution is internationally mobile and ii) the extent to which environmentalists care about pollution in other countries. As long as pollution is sufficiently mobile or as long as environmentalists are primarily concerned with environmental protection in their country, a rise of environmentalism reduces pollution. However, our analysis shows that there is no guarantee that a reduction of pollution will be the outcome in situations where pollution is immobile and environmentalists care a lot about pollution in other countries. Based on data for sulfur emission in Europe and America (see Appendix), several countries, including Canada, Turkey, Russia, Romania, France and Germany, satisfy the (necessary) condition for this to happen. Although, for most other European countries and the US, sulfur emission is sufficiently mobile to rule out adverse environmental consequences, the evidence suggests that we have identified more than a theoretical curiosity.

The rise of environmentalism is exogenous to our model. There is a significant literature that investigates the link between income growth and environmental quality [see, e.g., Grossman and Krueger (1995) and Hilton and Levinson (1998)] finding an inverse-U-shaped relationship. It would be of considerable interest in future research to link more explicitly the rise of environmentalism to income growth and assimilation of information about the environmental consequences of production.

Acknowledgment I am grateful to Rolf Bommer, Jan Rose Soerensen, Per Fredriksson, Torsten Persson, the participants in the 1998 meeting of the European Public Choice Society, the 1999 winter meeting of the Econometric Society, and the Summer School in Political Economy at CORE 1999 for comments and helpful suggestions. Finally, I am grateful to David Newbery for letting me use his EMEP data on sulphur deposition budgets in Europe. All remaining errors and misperspections are mine. 


\section{References}

AidT, T. (1998a): "The Political Economy of Lobby Groups, Applications to Environmental Policy, Trade Policy and Rent-Seeking," Ph.D. thesis, Department of Economics, University of Aarhus, Denmark.

AiDT, T. S. (1998b): "Political Internalization of Economic Externalities and environmental policy," Journal of Public Economics, 69, 1-16.

Antweiler, W., B. R. Copeland, and M. S. Taylor (1998): "Is Free Trade Good for the Environment," NBER working paper, 6707.

Barrett, S. (1994a): "Self-Enforcing International Environmental Agreements," Oxford Economic Papers, 46, 878-894.

- (1994b): "Strategic Environmental Policy and International Trade," Journal of Public Economics, 54, 325-338.

Bernheim, B. D., and M. Whinston (1986): "Menu Auctions, Resource Allocation, and Economic Influence," Quarterly Journal of Economics, $101,1-31$.

Bommer, R. (1996): "Environmental regulation of production processes in the European Union: A political-economy approach.," Aussenwirtschaft, $51,559-582$.

BRANDER, J. (1981): "Intra-industry trade in identical commodities," Journal of International Economics, 11, 1-14.

Brander, J., and B. Spence (1984): "Trade Warfare: Tariffs and Cartels," Journal of International Economics, 16, 227-42.

Brander, J., And B. Spencer (1985): "Fxport Subsidies and International Market Share Rivalry," Journal of International Economics, 18, 83100 .

Buchanan, M., and G. Tullock (1975): "Polluters' Profit and Political Response: Direct Controls versus Taxes," American Economic Review, 65, $139-47$. 
Carraro, C., and D. Siniscalco (1991): "The international protection of the environment: Voluntary agreements among sovereign countries," in The Protection of Trans-National Commons, ed. by P. Dasgupta, K. G. Maler, and A. Vercelli. Clarendon, Oxford.

- (1992): "The International Dimension of Environmental Policy," European Economic Review, 36, 379-387.

Copeland, B. R., and M. S. Taylor (1994): "North-South Trade and the Environment," Quarterly Journal of Economics, pp. 755-787.

Dijkstra, B. R. (1998): "Interest Group Influence on Environmental Policy. The Professional's View," Paper presented at the annual meeting of the European Public Choice Soiciety, Gothenburg.

Dixit, A. (1996): "Special-Interest Lobbying and Endogenous Commodity Taxation," Eastern Economic Journal, 22, 375-388.

Dixit, A., G. M. Grossman, and E. Helpman (1997): "Common agency and coordination: general theory and application to government policy making," Journal of Political Economy, 105, 752-769.

Eurostat (1974-96): "Eurobarometer," (various numbers), various issues.

Fredriksson, P. (1997): "The Political Economy of Pollution Taxes in a Small Open Economy," Journal of Environmental Economics and Management, 33, 44-58.

Frijof-Nansen-Institute (1994): Green Globe Yearbook. Oxford University Press.

Grossman, G. M., and E. Helpman (1994): "Protection for Sale," American Economic Review, 84, 833-850.

- (1996): "Election Competition and Special Interest Politics," Review of Economic Studies, 63, 265-286.

Grossman, G. M., and A. B. Krueger (1995): "Economic Growth and the Environment," Quarterly Journal of Economics, pp. 353-377. 
Hillman, A., AND H. URSPRUng (1992): "The Influence of Environmental Conserns on the Political Determination of Trade Policy," in The Greening of World Trade Issues, ed. by K. Anderson, and R. Blackhurst, chap. 10, pp. 193-220. Harvester Wheatsheaf, New York.

Hilton, F. H., And A. Levinson (1998): "Factoring the Environmental Kuznets Curve: Evidence from Automotive Lead Emissions," Journal of Environmental Economics and Management, 35, 126-141.

Hoekman, B., And M. Leidy (1992): Environmental Policy Formation in a Trading Economy: A Public Choice Perspectivechap. 11, pp. 221-246. Harvester Wheatsheaf.

Hoel, M. (1991): "Global Environmental Problems: The Effect of Unilateral Actions Taken by One Country," Journal of Environmental Economics and Management, 20, 55-70.

Jaffe, A. B., S. R. Peterson, P. R. Portney, and R. Stavins (1995): "Environmental Regulation and the Competitiveness of U.S. Manufacturing: What Does the Evidence Tell Us?," Journal of Economic Literature, XXXIII, 132-162.

Kober, A. (1998): "Why Everybody Loves Flipper: The Political-Economy of the U.S. Dolphin-Safe Laws," European Journal of Political Economy, $14,475-509$.

Marshali, L. (1998): "Economic Instruments and the Business Use of Energy," HM Treasury.

Merrifield, J. (1988): “The Impact of Selected Abatement Strategies on Transnational Pollution, the Terms of Trade and Factor Rewards: A General Equilibrium Approach," Journal of Environmental Economics and Management, 15, 259-284.

Murdoch, J., T. Sandler, and K. Sargent (1997): "A Tale of Two Collectives: Sulphur versus Nitrogen Oxides Emission Reduction in Europe," Economica, 64, 281-301.

Newbery, D. (1990): “Acid Rain,” Economic Policy, 11, 298-345.

OECD (1998): Environmental Taxes and Green Tax Reform. Paris. 
Olson, M. (1965): The logic of collective action. Harvard University Press, Harvard, MA.

Pethig, R. (1976): "Pollution, Welfare and Environmental Policy in the Theory of Comparative Advantage," Journal of Environmental Economics and Management, 2, 160-169.

Porter, M. (1994): “America's Green Strategy," Scientific America, 168.

Rauscher, M. (1997): International trade, factor movements, and the environment. Oxford University Press, Oxford.

Schleich, J. (1999): "Environmental Quality with Endogenous Domectic and Trade Policies," European Journal of Political Economy, 15, 53-71.

Siebert, H., J. Eichberger, R. Gronych, and R. Pething (1980): Trade and environment, a theoretical enquiry. Elsevier, Amsterdam.

Svendsen, G. (1998): Public Choice and Environmental Regulation. Edward Elgar, Cheltenham, UK.

Ulph, A. (1997): "International Trade and the Environment: A Survey of Recent Economic Analysis," in The International Yearbook of Environmental and Resource Economics 1997/1998: A Survey of Current Issues, ed. by F. Folmer, and T. Tietenberg, pp. 205-243. Edward Elgar.

(1998): "Political Institutions and the Design of Environmental Policy in a Federal System with Asymmetric Information," European Economic Review, 42, 583-592.

\section{Appendix}

Table 3 summarizes the transportation patterns of sulphur emission in Europe in 1992. The Table contains information about 36 European countries covered by the European Monitoring and Evaluation Program (EMEP). The EMEP is discussed in more detail in Newbery (1990). For each country, we calculate the proportion of total sulphur emission from sources within that country that is deposited within the country. Using our previous notation, this defines $\alpha_{A A}$ as we think of the particular country under consideration as 
country $A$. For each country, we also calculated the proportion of total sulphur emission from all countries minus the country under consideration that is not deposited in that particular country. Using our previous notation, this defines $\alpha_{B B}$ as we think of the 35 other countries as country $B$. Recall that $\eta_{A}$ is the responsiveness of emission from sources within the country under consideration ("firm $A$ ") relative to that of sources in the other countries ("firm $B$ ") to a change in the tax rate in the country under consideration (" $t_{A}$ "). Using the values of $\alpha_{A A}$ and $\alpha_{B B}$, we calculate two critical values, denoted $\eta_{A}^{S 3}$ and $\eta_{A}^{S 1}$ as follows:

$$
\begin{aligned}
& \left(1-\alpha_{B B}\right)-\eta_{A}^{S 3} \alpha_{A A}=0 \\
& \alpha_{B B}-\eta_{A}^{S 1}\left(1-\alpha_{A A}\right)=0
\end{aligned}
$$

Equation (21) defines the value of $\eta_{A}$ at which $\frac{\partial E_{A}}{\partial t_{A}}=0$. For $\eta_{A}$ greater than $\eta_{A}^{S 3}, \frac{\partial E_{A}}{\partial t_{A}}$ is negative and vice versa. From Table 3 , we see that the values of $\eta_{A}^{S 3}$ are close to zero and so, scenario 3 , which requires $\eta_{A}<\eta_{A}^{S 3}$, is not empirically relevant. Equation (22) defines the value of $\eta_{A}$ at which $\frac{\partial E_{B}}{\partial t_{A}}=0$. For $\eta_{A}$ less than $\eta_{A}^{S 3}, \frac{\partial E_{A}}{\partial t_{A}}$ is positive and vice versa. If $\eta_{A}$ is 2 , i.e., if "firm $A$ " is twice as responsive to $t_{A}$ as "firm $B$ ", then $\frac{\partial E_{R}}{\partial t_{A}}>0$, for countries such as Turkey, Russia and Romania. If $\eta_{A}$ is 1.5 , then $\frac{\partial E_{B}}{\partial t_{A}}>0$ for many more countries, including Bulgaria, Spain, Czechoslovakia, Ukraine, Yugoslavia, Albania, Finland, France, Germany, Italia, Poland, Sweden, Portugal, Switzerland, the UK, Byelorussia and Bosnia. Hence, scenario 1 and 2 are both empirically relevant in Europe.

Similar results can be obtained from North American data. US sulphur emissions are responsible for about 50\% of Canada's sulphur depositions, while Canada is only to blame for about $10 \%-20 \%$ of US sulphur depositions [ Merrifield (1988)]. As in Europe, $\frac{\partial E_{A}}{\partial t_{A}}<0$. Assuming that $\eta_{A}=2, \frac{\partial E_{B}}{\partial t_{A}}>0$ for Canada and $\frac{\partial E_{B}}{\partial t_{A}}<0$ for the US. Again, both scenario 1 and 2 are empirically relevant, while scenario 3 is not. 
Table 3: Transportation of Sulphur in Europe, 1992 (\%) and critical values for scenario 1 and 3.

\begin{tabular}{|l|l|l|l|l|l|l|l|l|l|l|l|l|}
\hline Country & $\mathrm{AL}$ & $\mathrm{AT}$ & $\mathrm{BE}$ & $\mathrm{BG}$ & $\mathrm{CS}$ & $\mathrm{DK}$ & $\mathrm{FI}$ & $\mathrm{FR}$ & $\mathrm{DE}$ & $\mathrm{GR}$ & $\mathrm{HU}$ & $\mathrm{IS}$ \\
\hline$\alpha_{A A}$ & 0.31 & 0.38 & 0.23 & 0.47 & 0.36 & 0.14 & 0.39 & 0.41 & 0.42 & 0.30 & 0.33 & 0.29 \\
\hline$\alpha_{B B}$ & 0.999 & 0.991 & 0.997 & 0.992 & 0.982 & 0.998 & 0.992 & 0.980 & 0.971 & 0.993 & 0.992 & 1.000 \\
\hline$\eta_{A}^{S 3}$ & 0.002 & 0.009 & 0.003 & 0.008 & 0.019 & 0.002 & 0.008 & 0.020 & 0.030 & 0.007 & 0.008 & 0.000 \\
\hline$\eta_{A}^{S 1}$ & 1.45 & 1.61 & 1.30 & 1.86 & 1.53 & 1.16 & 1.63 & 1.66 & 1.67 & 1.42 & 1.48 & 1.42 \\
\hline $\mathrm{Country}$ & $\mathrm{IE}$ & $\mathrm{IT}$ & $\mathrm{LU}$ & $\mathrm{NL}$ & $\mathrm{NO}$ & $\mathrm{PL}$ & $\mathrm{PT}$ & $\mathrm{RO}$ & $\mathrm{ES}$ & $\mathrm{SE}$ & $\mathrm{CH}$ & $\mathrm{TR}$ \\
\hline$\alpha_{A A}$ & 0.29 & 0.42 & 0.19 & 0.18 & 0.33 & 0.44 & 0.39 & 0.51 & 0.47 & 0.36 & 0.43 & 0.57 \\
\hline$\alpha_{B B}$ & 0.999 & 0.998 & 1.000 & 0.995 & 0.993 & 0.964 & 0.999 & 0.983 & 0.993 & 0.990 & 0.996 & 0.987 \\
\hline$\eta_{A}^{S 3}$ & 0.001 & 0.012 & 0.000 & 0.005 & 0.007 & 0.038 & 0.001 & 0.017 & 0.007 & 0.01 & 0.004 & 0.013 \\
\hline$\eta_{A}^{S 1}$ & 1.4 & 1.69 & 1.24 & 1.22 & 1.48 & 1.72 & 1.63 & 1.99 & 1.88 & 1.55 & 1.76 & 2.32 \\
\hline $\mathrm{Country}$ & $\mathrm{GB}$ & $\mathrm{BY}$ & $\mathrm{UA}$ & $\mathrm{M} \mathrm{D}$ & $\mathrm{RU}$ & $\mathrm{EE}$ & $\mathrm{LV}$ & $\mathrm{LT}$ & $\mathrm{SI}$ & $\mathrm{HR}$ & $\mathrm{BA}$ & $\mathrm{YU}$ \\
\hline$\alpha_{A A}$ & 0.36 & 0.41 & 0.51 & 0.29 & 0.83 & 0.19 & 0.25 & 0.32 & 0.33 & 0.33 & 0.37 & 0.46 \\
\hline$\alpha_{B B}$ & 0.994 & 0.989 & 0.967 & 0.997 & 0.908 & 0.998 & 0.997 & 0.996 & 0.997 & 0.995 & 0.996 & 0.991 \\
\hline$\eta_{A}^{S 3}$ & 0.006 & 0.011 & 0.034 & 0.003 & 0.101 & 0.002 & 0.003 & 0.004 & 0.003 & 0.005 & 0.004 & 0.010 \\
\hline$\eta_{A}^{S 1}$ & 1.55 & 1.68 & 1.97 & 1.40 & 5.45 & 1.23 & 1.33 & 1.47 & 1.49 & 1.48 & 1.59 & 1.83 \\
\hline
\end{tabular}

Source: Calculated on the basis of data from EMEP (Monitoring and Evaluation Program). The underlying data are available from the author as an Excel file. 


\section{Appendix (Available on request)}

This appendix shows how production patterns, emission patterns, profits, consumer's surplus and tax revenue are affected by a change in $t_{A}$. From the firms' first order conditions, we get for the market in country $A$ :

$$
\begin{aligned}
& F_{A A}\left(x_{A A}, x_{B A}, t_{A}, t_{B}\right)=p_{A}^{\prime} x_{A A}+p_{A}-c_{A}-t_{A}=0 \\
& F_{B A}\left(x_{A A}, x_{B A}, t_{A}, t_{B}\right)=p_{A}^{\prime} x_{B A}+p_{A}-c_{B}-t_{B}=0 .
\end{aligned}
$$

The Implicit Function Theorem states that $F_{A A}=0$ and $F_{B A}=0$ implicitly define continuous functions

$$
\begin{aligned}
& x_{A A}=x_{A A}\left(t_{A}, t_{B}\right) \\
& x_{B A}=x_{B A}\left(t_{A}, t_{B}\right)
\end{aligned}
$$

and that these functions have continuous partial derivative if $F_{A A}$ and $F_{B A}$ have continuous partial derivatives and the following Jacobian determinant is non-zero:

$$
\begin{aligned}
\Delta_{A} & =\left|J_{A}\right|=\left|\begin{array}{cc}
p_{A}^{\prime \prime} x_{A A}+2 p_{A}^{\prime} & p_{A}^{\prime \prime} x_{A A}+p_{A}^{\prime} \\
p_{A}^{\prime \prime} x_{B A}+p_{A}^{\prime} & p_{A}^{\prime \prime} x_{B A}+2 p_{A}^{\prime}
\end{array}\right| \\
& =\left(p_{A}^{\prime \prime} x_{A A}+2 p_{A}^{\prime}\right)\left(p_{A}^{\prime \prime} x_{B A}+2 p_{A}^{\prime}\right)-\left(p_{A}^{\prime \prime} x_{A A}+p_{A}^{\prime}\right)\left(p_{A}^{\prime \prime} x_{B A}+p_{A}^{\prime}\right) \\
& =p_{A}^{\prime}\left[\left(p_{A}^{\prime \prime} x_{B A}+p_{A}^{\prime}\right)+\left(p_{A}^{\prime \prime} x_{A A}+2 p_{A}^{\prime}\right)\right] .
\end{aligned}
$$

It follows from the second order conditions $\left(p_{A}^{\prime \prime} x_{A A}+2 p_{A}^{\prime}<0\right)$ and the assumption that quantities are strategic substitutes $\left(p_{A}^{\prime \prime} x_{B A}+p_{A}^{\prime}<0\right)$ that $\Delta_{A}>0$.

1) Total differentiate equations (23) and (24) and rewrite in matrix notation:

$$
\begin{aligned}
& J_{A}\left(\begin{array}{c}
\frac{\partial x_{A A}}{\partial t_{A}} \\
\frac{\partial x_{B A}}{\partial t_{A}}
\end{array}\right)=\left(\begin{array}{l}
1 \\
0
\end{array}\right) \\
& J_{A}\left(\begin{array}{c}
\frac{\partial x_{A A}}{\partial t_{B}} \\
\frac{\partial x_{B A}}{\partial t_{B}}
\end{array}\right)=\left(\begin{array}{l}
0 \\
1
\end{array}\right)
\end{aligned}
$$

Using Cramer's rule, we find that

$$
\frac{\partial x_{A A}}{\partial t_{A}}=\frac{\left(p_{A}^{\prime \prime} x_{B A}+2 p_{A}^{\prime}\right)}{\Delta_{A}}<0
$$




$$
\frac{\partial x_{B A}}{\partial t_{A}}=-\frac{\left(p_{A}^{\prime \prime} x_{B A}+p_{A}^{\prime}\right)}{\Delta_{A}}>0
$$

Total supply to market $A$ is $x_{A}=x_{A A}+x_{B A}$ and

$$
\frac{\partial x_{A}}{\partial t_{A}}=\frac{-\left(p_{A}^{\prime \prime} x_{B A}+p_{A}^{\prime}\right)+\left(p_{A}^{\prime \prime} x_{B A}+2 p_{A}^{\prime}\right)}{\Delta_{A}}=\frac{p_{A}^{\prime}}{\Delta_{A}}<0
$$

Define $\Phi_{B A}\left(t_{A,} t_{B}\right)=p_{A}^{\prime \prime} x_{B A}+2 p_{A}^{\prime}$ and $\bar{\Phi}_{B A}\left(t_{A}, t_{B}\right)=p_{A}^{\prime \prime} x_{B A}+p_{A}^{\prime}$. Take the partial derivatives:

$$
\begin{gathered}
\frac{\partial \Phi_{B A}}{\partial t_{A}}=\frac{p_{A}^{\prime \prime \prime} x_{B A} p_{A}^{\prime}}{\Delta_{A}}+\frac{p_{A}^{\prime \prime}}{\Delta_{A}}\left(-p_{A}^{\prime \prime} x_{B A}+p_{A}^{\prime}\right) \\
\frac{\partial \bar{\Phi}_{B A}}{\partial t_{A}}=\frac{p_{A}^{\prime \prime \prime} x_{B A} p_{A}^{\prime}}{\Delta_{A}}-\frac{p_{A}^{\prime \prime}}{\Delta_{A}}\left(p_{A}^{\prime \prime} x_{B A}\right)
\end{gathered}
$$

Moreover, notice that

$$
\frac{\partial \Delta_{A}}{\partial t_{A}}=p_{A}^{\prime \prime \prime} \frac{\left(p_{A}^{\prime}\right)^{2}}{\Delta_{A}}\left(x_{A A}+x_{B A}\right)+p_{A}^{\prime \prime} \frac{\Delta_{A}+4\left(p_{A}^{\prime}\right)^{2}}{\Delta_{A}}
$$

Unless we put restrictions on $p_{A}^{\prime \prime \prime}$ and $p_{A}^{\prime \prime}$, the sign of these derivatives is ambiguous. Therefore, it is not surprising that the effect of a change in $t_{A}$ on marginal production is ambiguous as well. Assuming that $p^{\prime \prime \prime}=0$, the two (relevant) second derivatives of $x_{A A}\left(t_{A}, t_{B}\right)$ and $x_{B A}\left(t_{A}, t_{B}\right)$ are:

$$
\begin{gathered}
\frac{\partial^{2} x_{A A}}{\partial t_{A}^{2}} \mid p_{A}^{\prime \prime \prime}=0=\frac{\Delta_{A} \frac{\partial \Phi_{B A}}{\partial t_{A}}-\Phi_{B A} \frac{\partial \Delta_{A}}{\partial t_{A}}}{\Delta_{A}^{2}} \\
=-\frac{p_{A}^{\prime} p_{A}^{\prime \prime}}{\Delta_{A}^{3}}\left\{\left(1+\frac{2 p_{A}^{\prime \prime}}{p_{A}^{\prime}}\right) \Delta_{A}+4 p_{A}^{\prime} \Phi_{B A}\right\} \\
\frac{\partial^{2} x_{B A}}{\partial t_{A}^{2}} \mid p_{A}^{\prime \prime \prime}=\mathbf{0}=-\frac{\Delta_{A} \frac{\partial \bar{\Phi}_{B A}}{\partial t_{A}}-\bar{\Phi}_{B A} \frac{\partial \Delta_{A}}{\partial t_{A}}}{\Delta_{A}^{2}} \\
=-\frac{p_{A}^{\prime \prime}}{\Delta_{A}^{3}}\left\{p_{A}^{\prime \prime} x_{B A}\left(2 \Delta_{A}+4\left(p_{A}^{\prime}\right)^{2}\right)+p_{A}^{\prime}\left(\Delta_{A}+4\left(p_{A}^{\prime}\right)^{2}\right)\right\}
\end{gathered}
$$

If $p_{A}^{\prime \prime}=0$, the two second derivatives are zero. 
2) Discharge of emission from the firm in country $A$ is $e_{A}=x_{A A}+x_{A B}$ with

$$
\frac{\partial e_{A}}{\partial t_{A}}=\frac{\left(p_{A}^{\prime \prime} x_{B A}+2 p_{A}^{\prime}\right)}{\Delta_{A}}+\frac{\left(p_{B}^{\prime \prime} x_{B B}+2 p_{B}^{\prime}\right)}{\Delta_{B}}<0,
$$

where $\Delta_{B}=p_{B}^{\prime}\left[\left(p_{B}^{\prime \prime} x_{A B}+p_{B}^{\prime}\right)+\left(p_{B}^{\prime \prime} x_{B B}+2 p_{B}^{\prime}\right)\right]>0$. Discharge of emission from firm $B$ is $e_{B}=x_{B B}+x_{B A}$ with

$$
\frac{\partial e_{B}}{\partial t_{A}}=-\frac{\left(p_{B}^{\prime \prime} x_{B B}+p_{B}^{\prime}\right)}{\Delta_{B}}-\frac{\left(p_{A}^{\prime \prime} x_{B A}+p_{A}^{\prime}\right)}{\Delta_{A}}>0 .
$$

Total emission is $E=e_{A}+e_{B}$ with

$$
\frac{\partial E}{\partial t_{A}}=\frac{p_{A}^{\prime}}{\Delta_{A}}+\frac{p_{B}^{\prime}}{\Delta_{B}}<0
$$

3) The (total) profit function of firm $A$ is:

$$
\pi_{A}^{*}(.)=p_{A}(.) x_{A A}(.)+p_{B}(.) x_{A B}(.)-\left(c_{A}+t_{A}\right) x_{A}(.) .
$$

From the Envelope Theorem, we get:

$$
\begin{aligned}
\frac{\partial \pi_{A}}{\partial t_{A}}= & p_{A}^{\prime}(.) x_{A A}(.) \frac{\partial x_{B A}}{\partial t_{A}}(.)+ \\
& p_{B}^{\prime}(.) x_{A B}(.) \frac{\partial x_{B B}}{\partial t_{A}}(.)- \\
& \left(x_{A A}(.)+x_{A B}(.)\right)<0
\end{aligned}
$$

Use equation (42) to calculate:

$$
\begin{aligned}
\frac{\partial^{2} \pi_{A}}{\partial t_{A}^{2}}= & p_{A}^{\prime \prime}\left[\frac{\partial x_{A A}}{\partial t_{A}}+\frac{\partial x_{B A}}{\partial t_{A}}\right] x_{A A} \frac{\partial x_{B A}}{\partial t_{A}}+ \\
& p_{B}^{\prime \prime}\left[\frac{\partial x_{B B}}{\partial t_{A}}+\frac{\partial x_{A B}}{\partial t_{A}}\right] x_{A B} \frac{\partial x_{B B}}{\partial t_{A}}+ \\
& p_{A}^{\prime}(.)\left[\frac{\partial x_{A A}}{\partial t_{A}} \frac{\partial x_{B A}}{\partial t_{A}}+x_{A A} \frac{\partial^{2} x_{B A}}{\partial t_{A}^{2}}\right]+ \\
& p_{B}^{\prime}(.)\left[\frac{\partial x_{A B}}{\partial t_{A}} \frac{\partial x_{B B}}{\partial t_{A}}+x_{A B} \frac{\partial^{2} x_{B B}}{\partial t_{A}^{2}}\right]- \\
& {\left[\frac{\partial x_{A A}}{\partial t_{A}}+\frac{\partial x_{A B}}{\partial t_{A}}\right] . }
\end{aligned}
$$


The sign of $\frac{\partial^{2} \pi_{A}}{\partial t_{A}^{2}}$ is, in general, ambiguous. However, if $p_{A}^{\prime \prime}=p_{B}^{\prime \prime}=0$, then $\frac{\partial^{2} \pi_{A}}{\partial t_{A}^{2}}=-\frac{7}{9}\left(\frac{1}{p_{A}^{\prime}}+\frac{1}{p_{B}^{\prime}}\right)>0$.

4) Consumer's surplus for consumers in country $A$ can be written as $u\left(x_{A A}()+.x_{B A}().\right)-p_{A}\left(x_{A A}()+.x_{B A}().\right)\left[x_{A A}()+.x_{B A}().\right]$. Using the fact that $p_{A}=\frac{\partial u}{\partial C_{A}}$, we get:

$$
\frac{\partial C S_{A}}{\partial t_{A}}=-\left[x_{A A}(.)+x_{B A}(.)\right] p_{A}^{\prime}(.)\left[\frac{\partial x_{A A}}{\partial t_{A}}+\frac{\partial x_{B A}}{\partial t_{A}}\right]<0 .
$$

The second derivative is:

$$
\begin{aligned}
\frac{\partial^{2} C S_{A}}{\partial t_{A}^{2}}= & -\left[\left[x_{A A}(.)+x_{B A}(.)\right] p_{A}^{\prime \prime}(.)+p_{A}^{\prime}(.)\right]\left[\frac{\partial x_{A A}}{\partial t_{A}}+\frac{\partial x_{B A}}{\partial t_{A}}\right]^{2} \\
& +\left[x_{A A}(.)+x_{B A}(.)\right] p_{A}^{\prime}(.)\left[\frac{\partial^{2} x_{A A}}{\partial t_{A}^{2}}+\frac{\partial^{2} x_{B A}}{\partial t_{A}^{2}}\right] .
\end{aligned}
$$

The sign of $\frac{\partial^{2} C S_{A}}{\partial t_{A}^{2}}$ is, in general, ambiguous. However, if $p_{A}^{\prime \prime}=0$, then $\frac{\partial^{2} C S_{A}}{\partial t_{A}^{2}}=\frac{-1}{9 p_{A}^{\prime}}>0$

5) The tax revenue collected in country $A$ is $R_{A}=t_{A} e_{A}$ and

$$
\frac{\partial R_{A}}{\partial t_{A}}=t_{A} \frac{\partial e_{A}}{\partial t_{A}}+e_{A}
$$

The second derivative is:

$$
\frac{\partial^{2} R_{A}}{\partial t_{A}^{2}}=t_{A} \frac{\partial^{2} e_{A}}{\partial t_{A}^{2}}+2 \frac{\partial e_{A}}{\partial t_{A}}
$$

If $p_{A}^{\prime \prime}=0$, then $\frac{\partial^{2} R_{A}}{\partial t_{A}^{2}}=\frac{4}{3}\left(\frac{1}{p_{A}^{\prime}}+\frac{1}{p_{B}^{\prime}}\right)<0$.

\section{Appendix (available upon request)}

In this appendix, we analyze the second order condition associated with equation (15). Calculate: 


$$
\begin{aligned}
\frac{\partial \Lambda_{A}(.)}{\partial t_{A}}= & \theta_{A} \frac{\partial^{2} R_{A}(.)}{\partial t_{A}^{2}}+\theta_{A} \frac{\partial^{2} C S_{A}(.)}{\partial t_{A}^{2}}+\left(\theta_{A}+\gamma_{A}^{P}\right) \frac{\partial^{2} \pi_{A}(.)}{\partial t_{A}^{2}} \\
& -\left(\theta_{A}+\gamma_{A}^{E}\right)\left(\beta_{A}\left(\frac{\partial E_{A}}{\partial t_{A}}\right)^{2}+\beta_{A} E_{A} \frac{\partial^{2} E_{A}}{\partial t_{A}^{2}}\right) \\
& -\left(\theta_{A} \bar{\gamma}_{A}^{E}+\gamma_{A}^{E}\right)\left(\delta_{A}\left(\frac{\partial E_{B}}{\partial t_{A}}\right)^{2}+\delta_{A} E_{B} \frac{\partial^{2} E_{B}}{\partial t_{A}^{2}}\right)
\end{aligned}
$$

The sign of the derivative is, in general, ambiguous but $\frac{\partial \Lambda_{A}(.)}{\partial t_{A}}<0$ if $\beta_{A}$ and $\delta_{A}$ are sufficiently large. If $p_{A}^{\prime \prime}=p_{B}^{\prime \prime}=0$ and $p_{A}^{\prime}=p_{B}^{\prime}=p^{\prime}$, then

$$
\begin{aligned}
\frac{\partial \Lambda_{A}(.)}{\partial t_{A}}= & \frac{1}{p^{\prime}}\left(\theta_{A}-\gamma_{A}^{P} \frac{14}{9}\right) \\
& -\left(\theta_{A}+\gamma_{A}^{E}\right)\left(\beta_{A}\left(\frac{2}{3} \frac{1}{p^{\prime}}\left(2 \alpha_{A A}-\alpha_{B A}\right)\right)^{2}\right) \\
& -\left(\theta_{A} \bar{\gamma}_{A}^{E}+\gamma_{A}^{E}\right)\left(\delta_{A}\left(\frac{2}{3} \frac{1}{p^{\prime}}\left(\alpha_{B B}-2 \alpha_{A B}\right)\right)^{2}\right)
\end{aligned}
$$

which is surely negative if $\left(\theta_{A}>\frac{14}{9}\right)$. 